\title{
Bovine valved xenograft conduits in the extracardiac Fontan procedure
}

\author{
Ghassan Baslaim, MD, Arif Hussain, MD, Amjad Kouatli, MD, and Ahmed Jamjoom, MD, \\ Jeddah, Saudi Arabia
}

$\mathrm{T}$ otal cavopulmonary connection has been proposed as a rational alternative to atriopulmonary connection for complex Fontan operations. de Leval and colleagues ${ }^{1}$ proposed the concept of direct cavopulmonary connection as a way to minimize kinetic energy loss in the Fontan circuit.

Total cavopulmonary anastomosis with the extracardiac conduit technique has gained favor because it streamlines the venous flow pattern and reduces the incidence of atrial arrhythmias. ${ }^{2}$ There are a number of potential advantages of the extracardiac conduit approach over other modifications of the Fontan procedure, including the improved hydrodynamics in the cavopulmonary connection. ${ }^{3}$ Conduits of different material have been used for the extracardiac Fontan procedure, examples of these conduits are the Dacron tube, the polytetrafluoroethylene tube (Gore-Tex; W. L. Gore \& Associates, Inc, Flagstaff, Ariz), the homograft, and the pericardial tube, and each one has advantages and disadvantages. ${ }^{4,5}$

Bovine jugular vein xenograft (Medtronic's Contegra, Medtronic, Inc, Minneapolis, Minn) has been used successfully to reconstruct the right ventricular outflow tract in patients with congenital heart disease, with promising early results. ${ }^{6}$ The Contegra conduit is a biologic valved conduit consisting of a glutaraldehyde-preserved heterologous bovine jugular vein with a trileaflet venous valve. The advantages of using the Contegra xenograft are easy availability, different size options, and the presence of a valve in the conduit.

In this report we present potential advantages of using a xenograft valved conduit to construct the extracardiac Fontan connection between the inferior vena cava (IVC) and the pulmonary artery (PA).

\section{Clinical Summary}

Between June 2002 and October 2002, 4 patients underwent the extracardiac Fontan procedure using the concept of inserting a valved conduit (Contegra) between the IVC and the PA. The procedure was approved by the hospital research and ethics committee, and informed consent was obtained from the parents of the

From the Department of Cardiovascular Diseases, King Faisal Specialist Hospital and Research Center, Jeddah, Saudi Arabia.

Received for publication Dec 10, 2002; accepted for publication Dec 19, 2002.

Address for reprints: Ghassan Baslaim, MD, MBC-J 16, PO Box 40047, Jeddah 21499, Saudi Arabia (E-mail: gbaslaim@ @otmail.com).

J Thorac Cardiovasc Surg 2003;126:586-8

Copyright $\odot 2003$ by The American Association for Thoracic Surgery $0022-5223 / 2003 \$ 30.00+0$

doi:10.1016/S0022-5223(03)00126-0 patients. All patients underwent complete preoperative cardiac evaluation, including a detailed echocardiogram with the Hewlett-

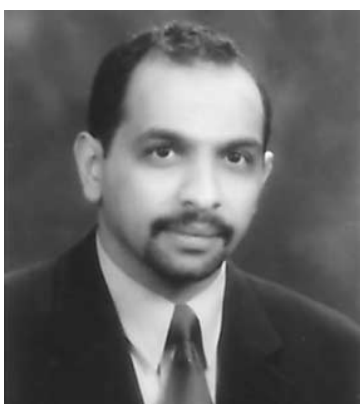

Dr Baslaim
Packard Sonos 5500 echocardiography system (Hewlett-Packard Company, Palo Alto, Calif) with the patient lying in the supine position. Complete hemodynamic, as well as angiographic, evaluation was performed during cardiac catheterization.

PATIENT 1. Patient 1 was a 4-year-old girl with transposed great vessels, large ventricular septal defect, single ventricle, and severe pulmonary stenosis whose previous operations were placement of a Blalock-Taussig shunt, followed by the bidirectional Glenn (BDG) procedure. She had good ventricular function, the mean PA pressure (MPAP) was $19 \mathrm{~mm} \mathrm{Hg}$, and the pulmonary vascular resistance (PVR) was 0.7 Wood units (WU).

PATIENT 2. Patient 2 was an 8-year-old girl with a hypoplastic right ventricle $(\mathrm{RV})$ and critical pulmonary stenosis who had a previous Blalock-Taussig shunt, followed by the BDG procedure. Her preoperative data showed good ventricular function, the MPAP was $15 \mathrm{~mm} \mathrm{Hg}$, and the PVR was $2.4 \mathrm{WU}$.

PATIENT 3. Patient 3 was a 4-year-old boy with transposed great vessels, double-inlet left ventricle, and double-outlet RV. He had previously undergone PA banding and the BDG procedure. His preoperative data showed good ventricular function, the MPAP was $18 \mathrm{~mm} \mathrm{Hg}$, and the PVR was $1.0 \mathrm{WU}$.

PATIENT 4. Patient 4 was a 3-year-old boy with tricuspid atresia and a hypoplastic RV who had previously undergone PA banding and the BDG procedure. He had a good preoperative ventricular function, the MPAP was $13 \mathrm{~mm} \mathrm{Hg}$, and the PVR was $0.6 \mathrm{WU}$.

Through a standard median sternotomy, the ascending aorta, pulmonary arteries, superior vena cava, and IVC were dissected free. The diameter of the IVC was inspected, and the appropriate size of the valved conduit was selected. The cannulation was performed by inserting a single aortic cannula and bicaval cannulation. The cannulas were adapted to the cardiopulmonary bypass circuit, and cardiopulmonary bypass was initiated.

Mobilization of PA branches was completed. The heart was arrested with cold blood cardioplegic solution administered in the antegrade fashion, followed by the opening of the atrium and unroofing of the coronary sinus and atrial septectomy if indicated. The main PA stump was divided, and the cardiac stump was sutured closed if necessary. The IVC was divided from the atrium, the atrial stump was closed with a 4-0 Prolene suture (Ethicon, Inc, Somerville, NJ), and the IVC cuff was prepared for anastomosis with the conduit. The extracardiac conduit was prepared, and the valve-opening direction was checked to maintain the flow direction from the IVC toward the PA (Figure 1). The caudal end was trimmed and fashioned for the anastomosis with the IVC cuff with 5-0 Prolene sutures. The valve's position was maintained nearly halfway between the IVC and the PA anastomotic suture lines. 


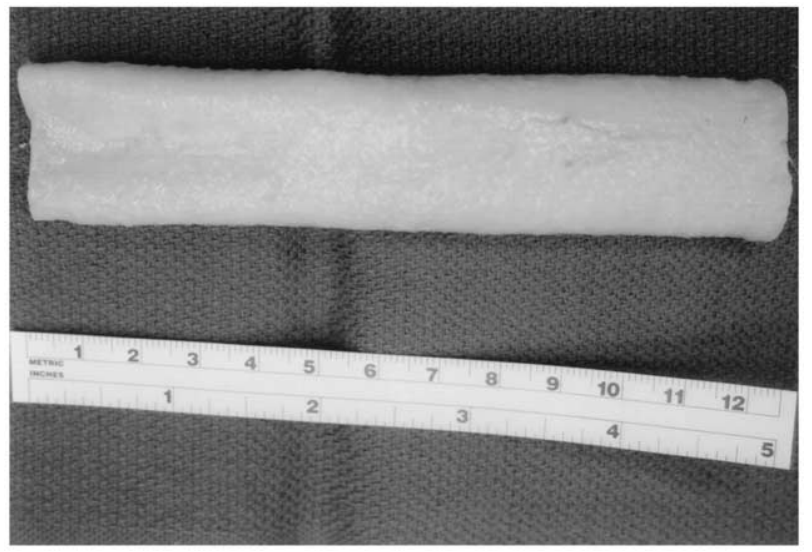

Figure 1. Representative macroscopic sample of the Contegra conduit. Note that the pointing green stitch mark indicates the outflow direction of the valve.

Then the cranial anastomosis was performed with 5-0 Prolene sutures between the conduit and the PA, and before the completion of the suture line, a 4.0-mm fenestration was constructed between the conduit and the atrium superior to the level of the valve. The cranial suture line was completed, the conduit was deaired, and the aortic crossclamp was removed (Figure 2).

\section{Results}

The cardiopulmonary bypass time and aortic crossclamp time ranged between 97 and 151 minutes (mean, 131.3 minutes) and 72 and 105 minutes (mean, 94.8 minutes), respectively. The ranges of mechanical ventilation duration, intensive care unit stay, chest tube duration, and hospital stay were 6 to 15 hours (average, 10.8 hours), 24 to 36 hours (average, 27 hours), 4 to 15 days (average, 8.8 days), and 8 to 19 days (average, 12.5 days), respectively. Postoperative room air oxygen saturation ranged between $88 \%$ and $96 \%$ (average, $91.8 \%$ ). The size of the Contegra conduit used was $20 \mathrm{~mm}$ in all patients, except in patient 1 a size $18-\mathrm{mm}$ conduit was chosen (Table 1).

In the immediate postoperative period and until discharge from the hospital, none of the patients had ascites, hepatomegaly, or abnormal liver function. Immediate postoperative echocardiography showed trivial turbulence and minimal reversal of blood flow in the hepatic veins and the IVC. Detailed echocardiograms were performed in all patients at the time of discharge, and the blood flow pattern in the IVC and the hepatic veins was evaluated by pulse-wave and color Doppler ultrasonography with the patient lying in the supine position. The assessment showed good ventricular function, no pericardial effusion, continuous forward flow in the IVC, and minimal reversal of flow in the hepatic veins, and the IVC was not dilated in any of the patients, as determined by 2-dimensional echocardiography. All patients were discharged home on oral aspirin for life and warfarin sodium for 3 months, with a targeted international normalized ratio of 2 to 2.5 .

\section{Discussion}

The use of an extracardiac IVC-PA connection has a number of theoretical advantages. It avoids extensive atrial suture lines and

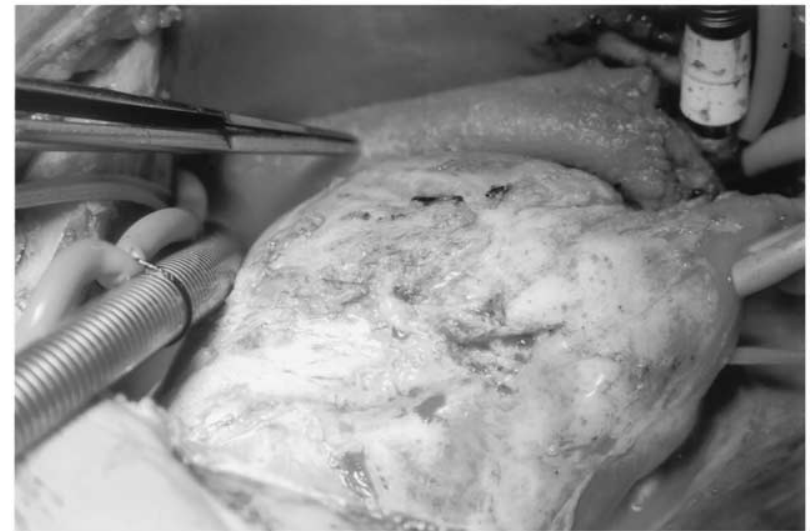

Figure 2. Contegra conduit sutured in position to the IVC (left) and the right PA (right). Note the forceps pointing toward the conduit.

hence arrhythmias and thromboembolism, prevents the exposure of the atrium to higher venous pressures, and theoretically provides better preservation of kinetic energy in the Fontan circuit. ${ }^{2,4}$ The hemodynamic consequence of this extracardiac conduit is better distribution of perfusion to both lungs. This was verified when ventilation-perfusion scans of the lungs were obtained. The investigations of de Leval and associates ${ }^{1,3}$ have added further guidance in optimizing the cavopulmonary connection geometry. Recent studies focusing on the pattern of infradiaphragmatic venous return in patients undergoing the Fontan procedure have provided further insight into hemodynamic characteristics unique to the Fontan circulation. These studies have shown that forward (antegrade) flow into the pulmonary circulation is significantly reduced in the upright position because of increased reversal of flow into the IVC and the hepatic veins caused by gravity. ${ }^{7,8}$ These findings might at least partly explain subnormal exercise tolerance in patients undergoing the Fontan procedure.

The use of a valved conduit in the Fontan procedure in the form of atriopulmonary connections was found to have no major complications attributable to the valve. ${ }^{9}$ As cited by Prenger and coworkers ${ }^{10}$ Fontan used the aortic homograft valves as the conduit and has had good long-term results. The Contegra bioprosthesis consists of a heterologous bovine jugular vein with a trileaflet venous valve and natural sinuses. The conduit has been preserved in buffered glutaraldehyde in a concentration low enough to preserve the flexibility of the leaflet material. The conduit is available in sizes 12 to $22 \mathrm{~mm}$ in both supported and unsupported models. This conduit has been used in different operative procedures, such as tetralogy of Fallot repair, the Ross procedure, and repair of truncus arteriosus. In several publications it has proved to be an excellent choice as an RV-PA conduit. ${ }^{6}$ The potential advantages of using the bovine jugular vein as a valve xenograft conduit between the IVC and the PA are excellent off-the-shelf availability, large variety of available sizes, easy tailoring and suturing, no need for proximal or distal extension, and presence of the valve.

We speculate that an additional benefit of using the Contegra xenograft could be that it provides a competent valve in the Fontan circulation, which might help by reducing the reversal of flow and maintaining better forward flow into the pulmonary circulation. 
TABLE 1. Summary of clinical data

\begin{tabular}{|c|c|c|c|c|c|c|c|c|}
\hline $\begin{array}{l}\text { Patient } \\
\text { no. } \\
\end{array}$ & $\begin{array}{c}\text { Age/ } \\
\text { sex }\end{array}$ & Diagnosis & $\begin{array}{l}\text { Previous } \\
\text { operation }\end{array}$ & $\begin{array}{c}\text { MPAP } \\
(\mathrm{mm} \mathrm{Hg})\end{array}$ & $\begin{array}{l}\text { PVR } \\
\text { (WU) } \\
\end{array}$ & $\begin{array}{c}\text { Conduit } \\
\text { size }(\mathrm{mm})\end{array}$ & $\begin{array}{c}\text { Postoperative } \\
\mathrm{O}_{2}(\%) \\
\end{array}$ & $\begin{array}{c}\text { Hospital stay } \\
\text { (d) }\end{array}$ \\
\hline 1 & $4 / F$ & $\begin{array}{l}\text { TGA, VSD, PS, } \\
\text { single ventricle }\end{array}$ & BT shunt, BDG & 19 & 0.7 & 18 & 90 & 8 \\
\hline 2 & $8 / \mathrm{F}$ & $\begin{array}{l}\text { HypoRV, } \\
\text { critical PS }\end{array}$ & BT shunt, BDG & 15 & 2.4 & 20 & 93 & 13 \\
\hline 3 & $4 / \mathrm{M}$ & TGA, DORV, DILV & PAB, BDG & 18 & 1.0 & 20 & 96 & 10 \\
\hline 4 & $3 / \mathrm{M}$ & TA, HypoRV & $\mathrm{PAB}, \mathrm{BDG}$ & 13 & 0.6 & 20 & 88 & 19 \\
\hline
\end{tabular}

TGA, Transposition of the great arteries; VSD, Ventricular septal defect; $P S$, pulmonary stenosis; BT, Blalock-Taussig; HypoRV, hypoplastic RV; DORV, double-outlet RV; DILV, double-inlet left ventricle; $P A B$, pulmonary artery banding; TA tricuspid atresia.

The Contegra valved conduit has been successfully used in constructing the right ventricular outflow tract, but we were concerned whether the valve in a nonpulsatile, passive Fontan circulation would facilitate smooth antegrade flow into the pulmonary circulation or act as a source of resistance to the flow. The facts that none of our patients had hepatomegaly or ascites on physical examination and that the postoperative echocardiograms showed excellent antegrade flow in the IVC, which was also not dilated, and minimal flow reversal in the hepatic veins supports the facilitation of smooth forward flow.

The purpose of this report is to present a new option for constructing an extracardiac Fontan connection with the Contegra xenograft that has not been previously published. The early echocardiographic results in our study appear to support the idea of minimizing the reversal of infradiaphragmatic venous flow, decreasing hepatic congestion, and possibly reducing the development of ascites.

Future prospective randomized studies are warranted to look into the differences among various Fontan connections by using the Contegra conduit, other conduits, and the lateral tunnel group. Also, the studies should include the assessment of venous flow, thrombogenicity, liver function, incidence of protein-losing enteropathy, and, most important, functional assessment and exercise tolerance.

\section{References}

1. de Leval M, Kilner P, Gewillig M, Bull C. Total cavopulmonary connection: a logical alternative to atrial pulmonary connection for complex Fontan operations. J Thorac Cardiovasc Surg. 1988;96:68295 .

2. McElhinney DB, Petrossian E, Reddy VM, Hanley FL. Extracardiac conduit Fontan procedure without cardiopulmonary bypass. Ann Thorac Surg. 1998;66:1826-8.

3. de Leval M, Dubini G, Migliavacca F, Jalali H, Camporini G, Redington A, et al. Use of computational fluid dynamics in the design of surgical procedures: application to the study of competitive flows in cavopulmonary connections. J Thorac Cardiovasc Surg. 1996;111: 502-13.

4. Okabe H, Nagata N, Kaneko Y, Kobayashi J, Kanemoto S, Takaoka T. Extracardiac cavopulmonary connection of Fontan procedure with autologous pedicled pericardium without cardiopulmonary bypass. J Thorac Cardiovasc Surg. 1998;116:1073-5.

5. Azakie A, McCrindle BW, Van Arsdell G, Benson LN, Coles J, Hamilton R, et al. Extraccardiac conduit versus lateral tunnel cavopulmonary connections at a single institution: impact on outcomes. J Thorac Cardiovasc Surg. 2001;122:1219-28.

6. Corno AF, Hurni M, Griffin H, Galal OM, Payot M, Sekarski N, et al. Bovine jugular vein as right ventricle-to-pulmonary artery valved conduit. J Heart Valve Dis. 2002;11:242-7.

7. Hsia TY, Khambadkone S, Redington AN, Migliavacca F, Deanfield JE, de Leval MR. Effects of respiration and gravity on infradiaphragmatic venous flow in normal and Fontan patients. Circulation. 2000; 102(Suppl III):III148-53.

8. Hsia TY, Khambadkone S, Deanfield JE, Taylor J, Migliavacca F, de Leval MR. Subdiaphragmatic venous hemodynamics in the Fontan circulation. J Thorac Cardiovasc Surg. 2001;121:436-47.

9. Laks H, Williams WG, Hellenbrand WE, Freedom RM, Talner NS, Rowe RD, et al. Results of right atrial to right ventricular and right atrial to pulmonary artery conduits for complex congenital heart disease. Ann Surg. 1980;192:382-9.

10. Prenger KB, Hess J, Cromme-Dijkhuis AH, Eijgelaar A. Porcinevalved Dacron conduits in Fontan procedures. Ann Thorac Surg. 1988;46:526-30. 